\title{
Representativeness of News and Exchange Rate Dynamics*
}

\author{
Sebastiano Manzan \\ CeNDEF, Department of Quantitative Economics, University of Amsterdam \\ Frank Westerhoff** \\ Department of Economics, University of Osnabrueck
}

\begin{abstract}
Guided by psychological evidence, we develop a behavioral exchange rate model in which investors' perception of fundamental shocks switches between two states. According to the representativeness heuristic, agents underestimate the informational content of news in calm periods, whereas they overreact to news if they encounter a series of distinct exchange rate changes. Simulations indicate that the model mimics the behavior of actual exchange rates quite well. For instance, we observe fat tails for the distribution of the returns and volatility clustering.
\end{abstract}

\section{Keywords}

exchange rates, news arrival, representativeness heuristic, over- and underreaction

\section{JEL Classification:}

F31, G14

\footnotetext{
* We gratefully acknowledge the helpful comments of two anonymous referees, which led to a substantial improvement of the paper. We also thank Jan Tuinstra for his constructive discussions.

** Contact: Frank Westerhoff, University of Osnabrueck, Department of Economics, Rolandstrasse 8, D-49069 Osnabrueck, Germany. Email: fwesterho@oec.uni-osnabrueck.de
} 


\section{Introduction}

This paper explores the relevance of news to exchange rate dynamics. As stated by the efficient market hypothesis, prices always reflect fundamental values (Fama 1970). Such a view has, of course, severe implications: The statistical features of exchange rate changes are fully explained by those of the underlying fundamental process. For instance, the distribution of the returns has fat tails because meaningful news occurs more frequently than suggested by the Normal distribution. Volatility clustering arises since the intensity of news alternates over time.

Market microstructure theory (see Lyons 2001 for a recent survey) offers more promising insight into the complex behavior of the exchange rate. For instance, Fan and Lyons (2001) find that extreme price changes at high frequency are associated with large net flows from financial institutions, whereas low frequency trends are associated with secular net flows from non-financial corporations. Note that the flow of such orders conveys dispersed information. It contains, e.g., the trades of those who analyze information. Since informative trades are mixed with uninformative trades, market efficiency crucially depends on how markets accomplish the difficult task of aggregating dispersed information. As shown by Lyons (2002), even markets with many rational traders may display lasting misalignments and high exchange rate variability.

In contrast, the chartist-fundamentalist approach regards news as a less substantial origin of price fluctuations. Exchange rate dynamics are mainly driven by the trading activity of heterogeneous interacting agents. While Day and Huang (1990) and Farmer and Joshi (2002) generate complex price fluctuations from nonlinear trading rules, Kirman (1991, 1993) investigates social interactions which may lead to herding behavior. In the framework of Brock and Hommes (1998), the traders switch between 
technical and fundamental predictors, depending on the rules' past performance. Lux and Marchesi (1999) generate realistic price movements by combining the latter two aspects. Osler (2002) investigates positive feedback dynamics resulting from stop-loss and take-profit orders. In a related framework, Hau (1998) shows that expectational errors tend to create excessive market entry and excess volatility.

However, exchange rates react to new information. Exploiting high frequency data, Andersen et al. (2002) conclude that announcement surprises trigger quick jumps in exchange rates. But how is news incorporated into exchange rates? Andersen et al. (2002) offer an intriguing channel of exchange rate determination: Traders change their investment positions due to the arrival of new information, and such a flow of orders causes exchange rates to adjust. Recent empirical studies support this mechanism. While Evans and Lyons (2002) report that the daily interdealer order flow explains an astonishing 60 percent of daily exchange rate movements, Evans and Lyons (2003) find that the order flow varies considerably with the macroeconomic news flow.

The aim of this paper is twofold: First, to propose a behavioral exchange rate model in which speculators' perception of news is based on robust psychological principles. Agents judge news as to whether it is similar to a typical class of news. Focusing on two regimes only, they think that if market historical volatility is high (low), current news must be important (unimportant). Over- and underreaction to news then drives the evolution of the exchange rate via the agents' orders. Second, to explore whether our model has the power to mimic actual exchange rate fluctuations. Among other things, simulations reveal fat tails for the distribution of the returns and volatility clustering. We thus conclude that the way in which speculators perceive news is essential to exchange rate dynamics. 
The remainder of this paper is organized as follows: Next, we survey the relationship between news and exchange rates in further depth and sketch some psychological findings on how agents may perceive and process information. Section 3 develops a simple behavioral news model. In section 4, we explore the extent to which the time series properties of exchange rates are reconcilable with our model. The last section concludes the paper.

\section{The Empirical Background}

\subsection{News and Exchange Rates}

What is news? According to Guillaume et al. (1997), news is a very broad concept covering events like a phone call of a customer who wants to make a large transaction, a conversation between foreign exchange dealers, forecasts of research centers, or general economic and political news releases. Although news is difficult to quantify, its impact on exchange rates is a heavily debated topic.

Goodhart et al. (1993) are among the first who relate movements in the exchange rate at high frequency to Reuters news announcements. These news messages appear in real time on the screen of professional traders. They detect an influence of news on the level of exchange rates, but the effect does not seem to be permanent. Andersen and Bollerslev (1998) find a somewhat stronger support. Largest returns appear to be linked to the release of public information such as certain macroeconomic announcements. More specifically, information arrivals induce abrupt price changes. The average price movement is typically attained within minutes. Using announcement surprises, defined as the difference between macroeconomic expectations and macroeconomic realizations, Andersen et al. (2002) are even more convinced that exchange rates obey news. 
Empirical attempts to link exchange rate movements to news are hampered by the difficulty in extracting the unexpected component of news. For this reason, Cheung and Chinn (2001) try to derive the impact of news from a survey study conducted among professional foreign exchange traders. Their main findings are as follows. News is rapidly incorporated into exchange rates. For the majority of the respondents, the bulk of the adjustment takes place within one minute. Moreover, traders believe that changes in fundamentals play a substantial role in the pricing of currencies.

Within our model, speculators trade on the basis of new information. The resulting order flow then decides the path of the exchange rate. This channel is backed up by two recent studies. Using order flow as a proximate determinant, Evans and Lyons (2002) develop a model which is strikingly successful in accounting for realized exchange rates. For the DEM/USD spot market, they find that $\$ 1$ billion of net dollar purchase increases the DEM price of a dollar by about 0.5 percent. Estimates for daily changes in log exchange rates show $\mathrm{R}^{2}$ statistics of above 60 percent.

Evans and Lyons (2003) disentangle how (macroeconomic) news enters exchange rates by distinguishing three sources of exchange rate variation: (1) News may be impounded directly into exchange rates, (2) news may induce order flow and thus may have an indirect effect on exchange rates, and (3) transactions unrelated to news may affect the exchange rate. They find that all three sources are significant. The total effect of news accounts for about 30 percent of price variation. About two thirds of the price effect from news is transmitted via order flow, with the remaining one third being the direct impounding of news in prices. Given the many problems associated with news studies, we find this evidence quite remarkable. 


\subsection{Investor Psychology}

Experimental evidence supports the notion of bounded rationality (Simon 1955, Tversky and Kahneman 1974, Smith 1991). People do not possess perfect knowledge, nor do they have the computational capacity to derive optimal actions. Instead, agents rely on a limited number of heuristic principles which reduce the complex tasks of assessing probabilities or predicting values to simpler judgmental operations. In general, these heuristics are quite useful, but sometimes they lead to systematic errors. Since people share rather similar rules of thumb, their aggregated impact is significant. For surveys about heuristics compare, for instance, Kahneman, Slovic and Tversky (1986), Shiller (1999) and Hirshleifer (2001).

Representativeness is one of the most salient heuristics. In the words of Tversky and Kahneman (1974, p. 1124): "Many of the probabilistic questions with which people are concerned belong to one of the following types: What is the probability that object A belongs to class $\mathrm{B}$ ? What is the probability that event A originates from process B? What is the probability that process $B$ will generate event A? In answering such questions, people typically rely on the representativeness heuristic, in which probabilities are evaluated by the degree to which $\mathrm{A}$ is representative of $\mathrm{B}$, that is by the degree to which A resembles B. For example, when A is highly representative of B, the probability that A originates from B is judged to be high. On the other hand, if A is not similar to B, the probability that A originates from B is judged to be low."

Several aspects deserve our attention. Similarity is typically identified on the basis of small samples (Kahneman and Tversky 1972). For instance, experiments by Grether (1980) reveal that individuals give too much weight to newly added evidence and too little to prior information. The use of the representativeness heuristic may therefore 
cause systematic errors, because people are too ready to believe that sequences of a certain type of events may have systematic causes. Put differently, people may perceive random clusters as reflecting a causal pattern. For instance, people mistakenly believe in "hot hands" among sports players, even when actual performance is very close to serially independent (Gilovich, Vallone and Tversky 1985). Such behavior is not limited to naive subjects. As reported by Tversky and Kahneman (1971), the statistical intuition of experienced researchers does not seem to be much better than that of other people.

In summary, individuals tend to classify things into discrete groups based on similar characteristics. Since the representativeness heuristic has been confirmed in various experimental settings, we adopt it for the foreign exchange market. Section 3 demonstrates that such behavior may lead to over- or underreliance on new information and thus may produce complex exchange rate dynamics.

\section{A Behavioral News Model}

\subsection{Motivation}

The foreign exchange market is the broadest, most active financial market in the world. For the BIS (2002), currency markets are highly speculative. The great majority of the trading volume reflects very short-term transactions. For example, intra-day operations account for 75 percent of the market volume. The prices that the main actors are prepared to bid and offer are observable from the relevant screen pages of financial news agencies such as Reuters. News is received quickly and plays a prominent role in the fast and hectic trading in currency markets.

Based on the empirical evidence, the model works as follows. The economy is continuously hit by random news that is incorporated into prices through the interplay 
of demand and supply. Our main focus is on speculators. If news is favorable, they will buy currency which drives prices up and vice versa. The dynamics of our model is driven by the agents' reactions to news. However, the exact meaning of new information is not clear. For simplicity, we consider two states only: Speculators either over- or underreact to new information depending on market historical volatility. If recent volatility exceeds a certain threshold, they overestimate the effects of news on exchange rates. In quite periods, news is underestimated. Note that such behavior is in line with the experimental finding mentioned above: Individuals form predictions based on how closely past outcomes fit certain categories. Periods of low volatility are associated with calm periods and vice versa.

Such behavior may create interesting dynamics. Suppose that a small number of large shocks hits the market at random. Since the agents pay too much attention to recent evidence, they conclude erroneously that these events are not random but have a fundamental cause. Since overreaction produces high volatility, the process is persistent. In fact, the behavior of the agents is self-fulfilling: Although they make objective mistakes, their predictions are better than a correct perception would be. A regime switching occurs only by chance. The arrival of a series of small shocks may, even in the case of overreaction, push the volatility below the threshold so that agents start to believe in a low volatility regime. ${ }^{1}$

\subsection{Setup}

The evolution of the fundamental exchange rate is due to the news arrival process and follows a random walk. Its $\log F$ is given by an arithmetic Brownian motion

\footnotetext{
${ }^{1}$ Theories of over- and underreaction for stock markets are proposed by Barberis et al. (1998), Daniel et al. (1998) and Odean (1998).
} 


$$
F_{t}=F_{t-1}+\eta_{t}
$$

The news $\eta$ is IID normally distributed with mean zero and (constant) variance $\sigma_{\eta}^{2}$.

The exchange rate is determined on an order driven market in which three types of agents are active: speculators, international firms and market makers. Speculators buy (sell) foreign currency if they expect a price increase (decrease). Their orders may be expressed as

$d_{t}^{S}=\alpha^{S}\left(E_{t}\left[S_{t+1}\right]-S_{t}\right)$,

where $\alpha^{S}$ is a positive reaction coefficient and $S$ is the log of the exchange rate.

Speculators watch the news arrival attentively. Expected exchange rate changes only depend on new information

$E_{t}\left[S_{t+1}\right]=S_{t}+\delta_{t} \eta_{t}$

The perception of news is, however, biased. We consider two states: over- and underreaction. For instance, if market historical volatility exceeds a certain threshold $K$, speculators overreact to news. This aspect is formalized as

$\delta_{t}=\left\{\begin{array}{ll}\delta^{O} & \text { for } \quad V_{t}(T)=\frac{1}{T} \sum_{i=1}^{T}\left|S_{t-i+1}-S_{t-i}\right| \geq K \\ \delta^{U} & \text { else }\end{array}\right.$,

where $\delta^{O}>1$ stands for overreaction and $0<\delta^{U}<1$ denotes underreaction. Market historical volatility $V$ (i.e. the memory of the agents) depends on the last $T$ trading periods.

Relative to the transactions of the speculators, the demand from internationally operating firms plays a minor but still significant role. The firms' orders are given as

$d_{t}^{F}=\alpha^{F}\left(F_{t}-S_{t}\right)$. 
The reaction coefficient $\alpha^{F}$ is positive. Note that (5) reflects a standard current account principle: If the exchange rate is above (below) its fundamental value, then exports exceed (fall short of) imports. Put differently, a current account surplus (deficit) results in the selling (buying) of currency.

All orders are mediated by market makers who supply excess demand from their inventory or accumulate inventory when there is excess supply. Market makers quote the exchange rate for period $t+1$ as

$S_{t+1}=S_{t}+\alpha^{M}\left(d_{t}^{S}+d_{t}^{F}\right)$,

where $\alpha^{M}$ is a positive reaction coefficient. Accordingly, buying drives prices up and selling drives them down.

The solution of the model is obtained by combining (1)-(6). Defining changes in $S$ as returns yields

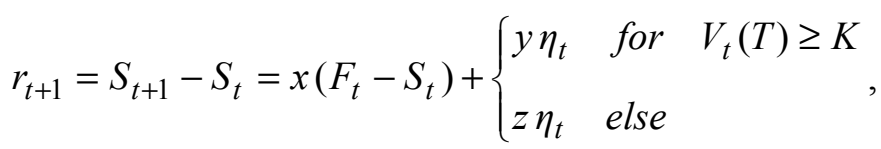

where $x=\alpha^{M} \alpha^{F}, y=\alpha^{M} \alpha^{S} \delta^{O}$ and $z=\alpha^{M} \alpha^{S} \delta^{U}$. Since (7) precludes closed analysis, we proceed with numerical analysis.

\subsection{Calibration}

Experimenting with the coefficients shows that the following parameter setting delivers dynamics which comes close to the real behavior of exchange rates: $x=0.001, y=1.35$, $z=0.65, K=0.0075, T=10, \sigma_{\eta}=0.01$. With the help of these values, it should be no problem to replicate our findings. We regard this as a valuable advantage over more complicated contributions. 
Some comments on the parameter setting seem to be appropriate. Since international trade transactions represent merely 1 percent of the total trading volume in foreign exchange markets (BIS 2002), a low impact of firms' orders seems to be reasonable. Over- and underreaction are both equal to 35 percent. Speculators pay attention to the fluctuations of the last 10 trading days. Such a memory seems to be in accordance with the representativeness heuristic (Kahneman and Tversky 1972, Grether 1980). The threshold is assumed to be around 0.75 percent, which roughly corresponds to the average volatility observed in the simulated time series. As usual, the volatility is calibrated via the standard deviation of the exogenous variable. For $\sigma_{\eta}=0.01$, we obtain extreme returns which are comparable to what is observed empirically.

\section{Simulation}

In this section, we investigate the extent to which our model is able to generate typical exchange rate movements. The dynamics of the exchange rate is often characterized by five features: (1) the trajectory of log exchange rates resembles a random walk, (2) exchange rates occasionally deviate from fundamentals, (3) exchange rates fluctuate strongly, (4) the distribution of returns possesses fat tails, and (5) periods of low volatility alternate with periods of high volatility. Recent surveys on these features including discussions of the relevant statistical techniques - include, for instance, Andersen and Bollerslev (1998), Guillaume et al. (1997) and Lux and Ausloos (2002).

We explore the dynamic behavior of actual and simulated exchange rates both numerically and graphically. Table 1 contains some statistics for DEM/USD and DEM/JPY exchange rates from 1974-1998. Both time series consist of 6264 daily observations. Table 1 also presents the minimum, median and maximum estimates of 
these statistics for 100 simulation runs. The top panel of figure 1 shows log DEM/USD exchange rates and the top panel of figure 2 displays simulated log exchange rates.

Table 1, Figure 1 and Figure 2 go about here

Several tests are in harmony with the random walk hypothesis. The penultimate panels of figures 1 and 2 reveal, for instance, the absence of any significant autocorrelation in the return series. From this perspective, exchange rates are unpredictable. The diffusion of a time series may be quantified by its Hurst exponent. Hurst exponents of around 0.5 suggest Brownian motion, whereas larger values indicate persistence and smaller values are a sign of anti-persistence. Applying the rescaledrange method, we find for simulated returns Hurst exponents between 0.5 and 0.56 , which correlates well with estimates obtained for DEM/USD and DEM/JPY data.

Distortions are difficult to measure empirically. The second panel of figure 1 exposes strong current account imbalances between Germany and the USA. Especially during the increase of the DEM/USD exchange rate in the mid 1980s, German exports to the USA boomed. The second panel of figure 2 presents relative deviations between the exchange rate and its fundamental value. Our model may produce strong and lasting misalignments. The distance between the exchange rate and its fundamental may temporarily be larger than 20 percent. Computing the average absolute deviation between $S$ and $F$ as an indicator of misalignments reveals an average distortion $D$ of around 5 percent. In the extreme case, $D$ might be as large as 10 percent.

The third panels of figures 1 and 2 exhibit the evolution of the returns in the time domain. Exchange rates fluctuate strongly. Largest daily returns are above 5 percent. During periods of overreaction, volatility is obviously excessive. The average relative absolute price change is 0.5 percent for the DEM/USD market and 0.44 percent for the 
DEM/JPY market. Calculating volatility for the simulated data yields values of $V=0.59-74$.

The fourth panels of figures 1 and 2 visualize the fat tail property. The left-hand panels display the probability density function of our time series. The right-hand panels contain the probability density functions of Normal distributions. Relative to the Normal distribution, one typically observes a higher concentration around the mean, thinner shoulders and more probability mass in the tails. Using the Hill tail index estimator to quantify the tail size, we ascertain that the tail index of DEM/USD and $\mathrm{DEM} / \mathrm{JPY}$ returns is in harmony with the tail indices of the simulated time series. For the largest 5 percent of the observations, $\gamma_{0.05}$ ranges mainly between 3.5 and 4 . The tail indices for DEM/USD and DEM/JPY returns are computed as 3.58 and 3.69, respectively.

Volatility is strongly correlated over time. Using absolute returns as a proxy for volatility shows that temporal independence is strongly rejected (compare the bottom panels of figures 1 and 2). One finds significant positive autocorrelation coefficients over an extended time horizon. To be precise, the autocorrelation function displays a hyperbolic decline. Long-term dependence is also captured by Hurst exponents which scatter between 0.6 and $0.7^{2}$

All in all, our model has the power to match the stylized facts of foreign exchange markets. Some popular statistical tests do not discriminate between real and artificial data. We find this noteworthy since our approach is relatively simple. Especially having fat tails and volatility clustering while having no autocorrelation in raw returns is for

\footnotetext{
${ }^{2}$ Several methods have been proposed to quantify long memory (see Kirman and Teyssière 2002 for a comprehensive survey). Note that for a time series with finite variance, the estimate of the Hurst exponent $H$ is related to the estimate of the fractional differencing parameter $d$ by the identity $H=d+0.5$. Moreover, the rate of decay of the autocorrelation function is given as $y=1-2 d$.
} 
may behavioral finance models still a challenge. Finally, we investigate what is driving the dynamics and what is causing the stylized facts.

Let us first consider how the model functions. Suppose that the market is in a tranquil state so that the speculators underestimate the changes in fundamentals. As a result, volatility stays persistently low. But shocks are normally distributed and a series of large shocks will eventually appear. Although the agents underreact to news, volatility increases. If the threshold is crossed, they start to overreact to news. The high volatility regime continues until a series of minor shocks emerges.

Now, the time series properties are straightforward. Since the dynamics is dominated by speculators' responses to stochastic news, the exchange rate path appears as a random walk. Due to misperceptions, the exchange rate disconnects from its fundamental. Nevertheless, exchange rate changes are correlated with news. ${ }^{3}$ The distortion is bounded by the current account reaction. The more the exchange rate is misaligned, the stronger the stabilizing impact of international trade transactions. ${ }^{4}$ In the high volatility regime, exchange rate fluctuations are obviously excessive. The endogenous switching between the two regimes causes both fat tails and volatility clustering.

\section{Conclusions}

News is undoubtedly a major variable driving foreign exchange dynamics. However, even professional traders experience difficulties when evaluating the meaning of news.

\footnotetext{
${ }^{3}$ Which is in harmony with the findings of Evans and Lyons (2002, 2003). A model with state dependent levels of noise trading would not display this property.

${ }^{4}$ There seems to exist an analogy to the finding of Fan and Lyons (2001) mentioned in the introduction: International trade transactions govern the dynamics in the long run, preventing the system from exploding. In the short run, the erratic movements are mainly due to the behavior of the speculators.
} 
Experimental evidence suggests that agents tend to misperceive new information systematically. By judging in simple categories, news is identified as important in periods of high volatility, whereas it is underrated in periods of low volatility. Although the only exogenous variable of our model is normally distributed, the artificial market displays some features that are remarkably similar to those observed in real markets. Overall, our approach exposes the meaningfulness of news and its perception for understanding exchange rate dynamics. From a general perspective, the latter observation is also relevant for practical policy recommendations. If central authorities provide more reliable information about fundamentals, the degree of misperception may decrease. In addition, calming down the dynamics should further prevent periods of overreaction. We are convinced that these aspects deserve more attention. 


\section{References}

Andersen, T. and Bollerslev, T. (1998): Deutsche Mark-Dollar Volatility: Intraday Activity Patterns, Macroeconomic Announcements, and Longer Run Dependencies, Journal of Finance, 53, 219-265.

Andersen, T., Bollerslev, T., Diebold, F. and Vega, C. (2002): Micro Effects of Macro Announcements: Real-Time Price Discovery in Foreign Exchange, NBER Working Paper Series, No. 8959.

Barberis, N., Shleifer, A. and Vishny, R. (1998): A Model of Investor Sentiment, Journal of Financial Economics, 49, 307-343.

BIS (2002): Central Bank Survey of Foreign Exchange and Derivatives Market Activity 2001, BIS: Basel.

Brock, W. and Hommes, C. (1998): Heterogeneous Beliefs and Routes to Chaos in a Simple Asset Pricing Model, Journal of Economic Dynamics Control, 22, 12351274.

Cheung, Y. and Chinn, M. (2001): Currency Traders and Exchange Rate Dynamics: A Survey of the US Market, Journal of International Money and Finance, 20, 439-471.

Daniel, K., Hirshleifer, D. and Subrahmanyam, A. (1998): Investor Psychology and Security Market Under- and Overreaction, Journal of Finance, 53, 1839-1886.

Day, R. and Huang, W. (1990): Bulls, Bears and Market Sheep, Journal of Economic Behavior and Organization, 14, 299-329.

Evans, M. and Lyons, R. (2002): Order Flow and Exchange Rate Dynamics, Journal of Political Economy, 110, 170-180.

Evans, M. and Lyons, R. (2003): How is Macro News Transmitted to Exchange Rates, NBER Working Paper Series, No. 9433.

Fama, E. (1970): Efficient Capital Markets: A Review of Theory and Empirical Work, Journal of Finance, 25, 383-417.

Fan, M. and Lyons, R. (2001): Customer Trades and Extreme Events in Foreign Exchange, in: Mizen, P. (Ed.): Monetary History, Exchange Rates and Financial Markets, Edward Elgar: Northampton, 160-179.

Farmer, D. and Joshi, S. (2002): The Price Dynamics of Common Trading Strategies, Journal of Economic Behavior and Organization, 49, 149-171. 
Gilovich, T., Vallone, R. and Tversky, A. (1985): The Hot Hand in Basketball: On the Misperception of Random Sequences, Cognitive Psychology, 17, 295-314.

Goodhart, C., Hall, S., Henry, S. and Pesaran, B. (1993): News Effects in a HighFrequency Model of the Sterling-Dollar Exchange Rate, Journal of Applied Econometrics, 8, 1-13.

Grether, D. (1980): Bayes Rules as a Descriptive Model: The Representativeness Heuristic, Quarterly Journal of Economics, 95, 537-557.

Guillaume, D., Dacorogna, M. Dave, R., Müller, U., Olsen, R. and Picet, O. (1997): From the Bird's Eye to the Microscope: A Survey of New Stylized Facts of the IntraDaily Foreign Exchange Markets, Finance Stochastics, 1, 95-129.

Hau, H. (1998): Competitive Entry and Endogenous Risk in the Foreign Exchange Market, Review of Financial Studies, 11, 757-787.

Hirshleifer, D. (2001): Investor Psychology and Asset Pricing, Journal of Finance, 56, 1533-1597.

Kahneman, D. and Tversky, A. (1972): Subjective Probability: A Judgment of Representativeness, Cognitive Psychology, 3, 430-454.

Kahneman, D., Slovic, P. and Tversky, A. (1986): Judgment under Uncertainty: Heuristics and Biases, Cambridge University Press: Cambridge.

Kirman, A. (1991): Epidemics of Opinion and Speculative Bubbles in Financial Markets, in: Taylor, M. (Ed.): Money and Financial Markets, Blackwell: Oxford, 354-368.

Kirman, A. (1993): Ants, Rationality, and Recruitment, Quarterly Journal of Economics, 108, 137-156.

Kirman, A. and Teyssière, G. (2002): Microeconomic Models for Long-Memory in the Volatility of Financial Time Series, Studies in Nonlinear Dynamics and Econometrics, 5, 281-302.

Lux, T. and Ausloos, M. (2002): Market Fluctuations I: Scaling, Multi-Scaling and their Possible Origins, in: Bunde, A. and Schellnhuber, H. (Eds.): Theories of Disaster: Scaling Laws Governing Weather, Body and Stock Market Dynamics, Springer: Berlin.

Lux, T. and Marchesi, M. (1999): Scaling and Criticality in a Stochastic Multi-Agent Model of a Financial Market, Nature, 397, 498-500. 
Lyons, R. (2001): The Microstructure Approach to Exchange Rates, MIT Press: Cambridge.

Lyons, R. (2002): Foreign Exchange: Macro Puzzles, Micro Tools, Federal Reserve Bank of San Francisco, Economic Review, 51-69.

Odean, T. (1998): Volume, Volatility, Price, and Profit When All Traders are Above Average, Journal of Finance, 53, 1387-1934.

Osler, C. (2002): Currency Orders and Exchange Rate Dynamics: An Explanation for the Predictive Success of Technical Analysis, Journal of Finance (in press).

Shiller, R. (1999): Human Behavior and the Efficiency of the Financial System, in: Taylor, J. and Woodford, M. (Eds.): Handbook of Macroeconomics, Elsevier: Amsterdam, 1305-1340.

Simon, H. (1955): A Behavioral Model of Rational Choice, Quarterly Journal of Economics, 9, 99-118.

Smith, V. (1991): Papers in Experimental Economics, Cambridge University Press: Cambridge.

Tversky, A. and Kahneman, D. (1971): Belief in the Law of Small Numbers, Psychological Bulletin, 76, 105-110.

Tversky, A. and Kahneman, D. (1974): Judgment Under Uncertainty: Heuristics and Biases, Science, 185, 1124-1131. 


\begin{tabular}{|c|c|c|c|c|c|c|c|}
\hline Time Series & $r_{\min }$ & $r_{\max }$ & $V$ & $D$ & $\gamma_{0.05}$ & $H_{r}$ & $H_{|r|}$ \\
\hline DEM/USD & -5.75 & 4.95 & 0.50 & - & 3.58 & 0.53 & 0.66 \\
\hline DEM/JPY & -3.84 & 8.94 & 0.44 & - & 3.69 & 0.57 & 0.63 \\
\hline Sim-Min & -3.68 & 3.62 & 0.59 & 2.99 & 3.37 & 0.50 & 0.60 \\
\hline Sim-Med & -4.43 & 4.47 & 0.66 & 5.48 & 3.89 & 0.53 & 0.66 \\
\hline Sim-Max & -6.21 & 5.91 & 0.74 & 10.27 & 4.74 & 0.56 & 0.70 \\
\hline
\end{tabular}

Table 1: Numerical Survey of Stylized Facts. Daily DEM/USD and DEM/JPY data from 1974-1998 (6264 observations). Sim-Min, Sim-Med and Sim-Max indicate the minimum, median and maximum estimates of the statistics obtained out of 100 simulated time series. All simulations are based on the same parameter setting and consist of 6264 observations. $r, V, D, \gamma_{\alpha}$ and $H$ denote the return, the volatility, the distortion, the tail index at significance level $\alpha$ and the Hurst exponent, respectively. 

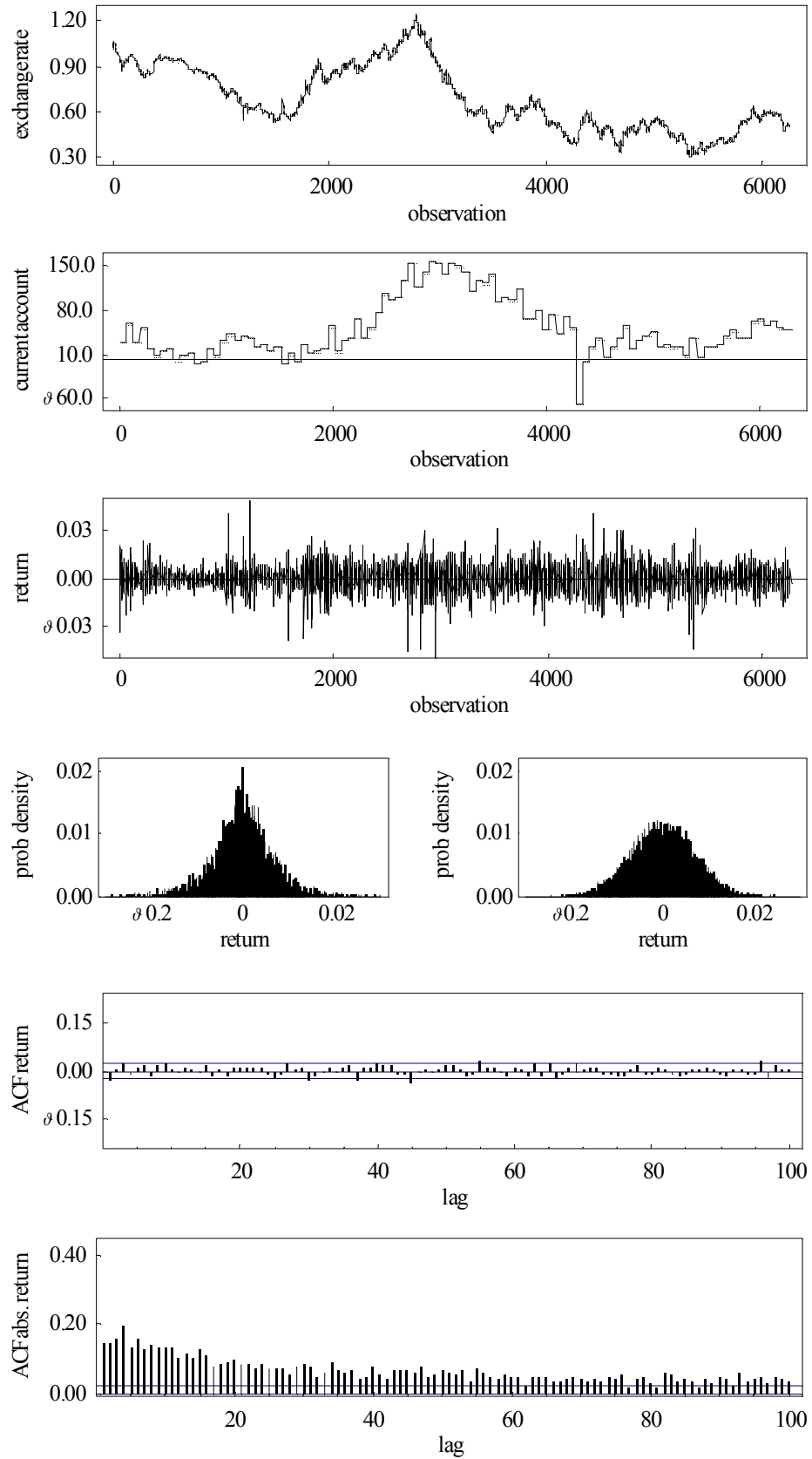

Figure 1: Stylized Facts of DEM/USD Exchange Rates. The first panel shows the log of the exchange rate (1974-1998, 6264 daily observations). The second panel displays the current account data in 1995 prices (1974-1998, 100 quarterly observations) and the third panel shows the distribution of the returns (left: DEM/USD, right: Normal distribution). The fourth panel depicts the autocorrelation function of raw returns and the last panel presents the autocorrelation function of absolute returns. 

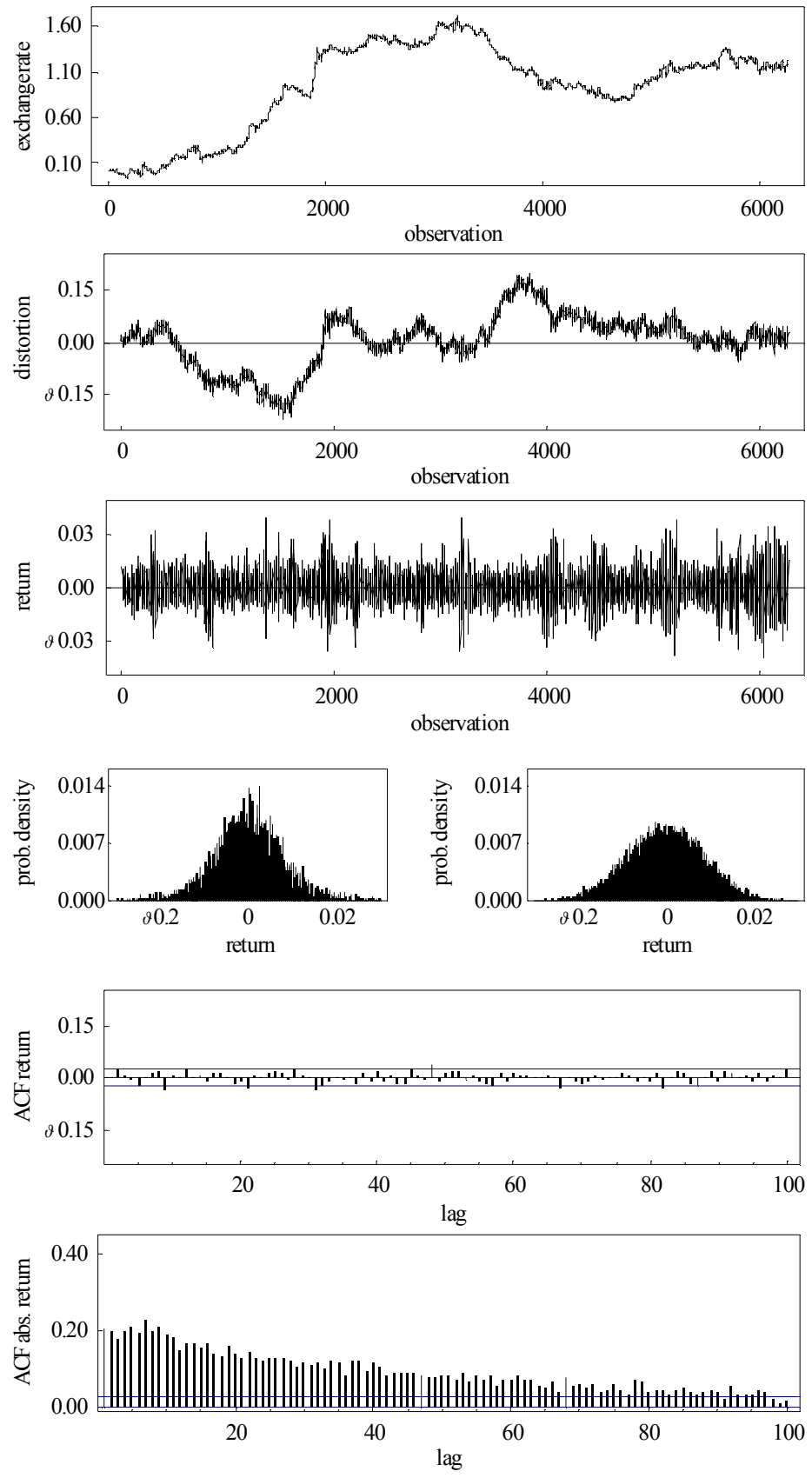

Figure 2: Stylized Facts of Simulated Exchange Rates. The first panel shows the log of the exchange rate (6264 observations) and the second panel depicts relative deviations from fundamentals. The third panel shows the distribution of the returns (left: simulated returns, right: Normal distribution). The fourth panel displays the autocorrelation function of raw returns and the last panel presents the autocorrelation function of absolute returns. 